\title{
Adult intrapulmonary and mediastinal lymphangioma causing haemoptysis
}

\author{
WILLIAM E HOLDEN, JAMES F MORRIS, RUZA ANTONOVIC, \\ THOMAS H GILL, STEVEN KESSLER
}

\author{
From the Departments of Medicine, Radiology, and Pathology, Portland Veterans Administration Medical \\ Center, and the Oregon Health Sciences University, Portland, Oregon, USA
}

We describe a middle aged man with a predominantly intrapulmonary lymphangioma, which rapidly enlarged and gave rise to persistent haemoptysis of sufficient severity to warrant surgical resection. Radiographic studies showed impairment of venous drainage in the area of the cyst and suggested a mechanism for haemorrhage into the lesion.

\section{Case report}

A 54 year old man, an ex-smoker, was noted to have a right hilar mass five years before presentation at our hospital. Thoracotomy had shown a cystic mass (benign lymphangiomatous cyst on frozen section) enveloping the structures of the right hilum. Resection was not attempted because a pneumonectomy would have been required. A radiograph four years later showed no change.

One month before admission to our hospital he developed a cough and haemoptysis of $30-40 \mathrm{ml}$ a day. Physical examination and laboratory studies revealed no abnormality apart from microcytic anaemia (haemoglobin $11.9 \mathrm{~g} / \mathrm{dl}$ ). Radiologically (fig 1 ) the mass was larger and contained several air-fluid levels. Fibreoptic bronchoscopy showed distortion and circumferential compression of all lobar and segmental airways of the right lung. Pulmonary angiography showed extrinsic compression of pulmonary arteries and veins; there was no evidence of a systemic arterial supply to the cystic lesion on aortography. Computed tomography with intravenous enhancement by contrast medium showed a multilobulated mass with several air-fluid levels and extrinsic compression of right bronchi, pulmonary arteries, and veins. Venous emptying was delayed. The mediastinal structures were normal.

Because of continued haemoptysis, a right pneumonectomy was performed. At operation a cystic structure was found, intertwined with and enveloping right hilar structures. A cystic appearing lymph node $(3.5 \times 1.9 \times 1.4 \mathrm{~cm})$, not contiguous with the intrapulmonary mass, was resected from the azygous vein and paratracheal area of the mediastinum. In the excised lung multiple cysts (up to $5 \mathrm{~cm}$ diameter), many filled with blood clot, were embedded in the hilum and the perihilar parenchyma. The basilar segments of the right lower lobe showed intra-alveolar haemorrhage and haemosiderin laden macrophages. The cysts were lined by flattened endothelium and had varying degrees of

Address for reprint requests: Dr William E Holden, Portland Veterans Administration Medical Center, 3710 SW Veterans Hospital Road, Portland, Oregon 97207, USA.

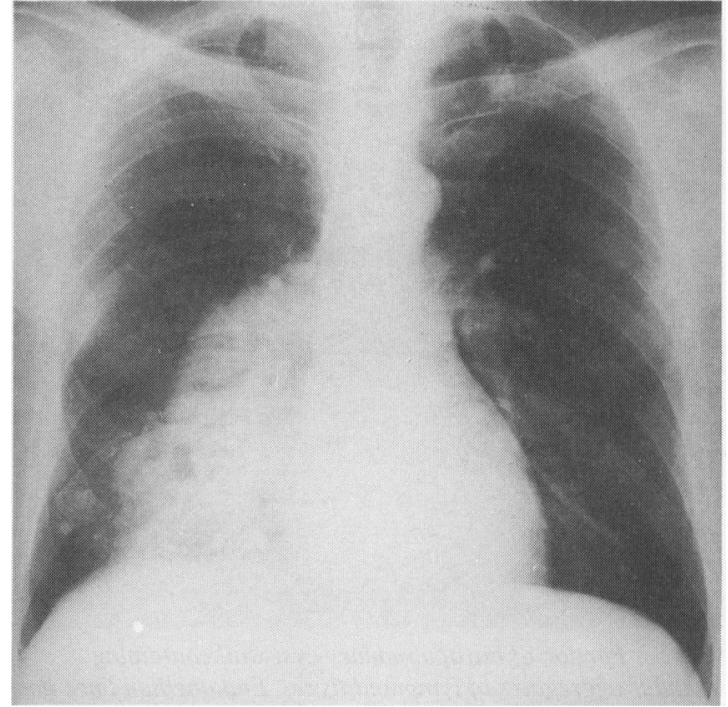

Fig 1 Posteroanterior chest radiograph taken on admission to our hospital. The right hilar mass was considerably larger than in previous prior radiographs and extended into the lower lung fields. Several pockets of air density were noted within the mass.

fibroblastic proliferation within their walls, which also contained focal aggregates of lymphocytes without germinal centres, and collections of thin walled, ectatic vascular spaces (fig 2). Similar structures, following the lines of lymphatic sinuses, were observed in the mediastinal node.

\section{Discussion}

Adult mediastinal lymphangiomas are congenital anomalies $^{12}$ similar to the cystic hygromas usually identified in the perinatal period. They may also be related to cystic lymphangiectasis, ${ }^{3}$ an almost uniformly fatal condition of neonates affecting predominantly the lung, but also associated with other developmental abnormalities. The cyst walls of lymphangiomas, however, are thicker and more fibrous than those of cystic lymphangiectasis, and adult lymphangioma rarely affects the lung parenchyma. ${ }^{45}$ Lymphangioma of both lung and mediastinum has not previously been described, but three cases reported as lymphangiectasis by Wagenaar et $\mathrm{al}^{6}$ in adolescents may be similar to our case.

Our patient was unusual on two counts. Firstly, the lesion showed no growth for four years, and then more than dou- 


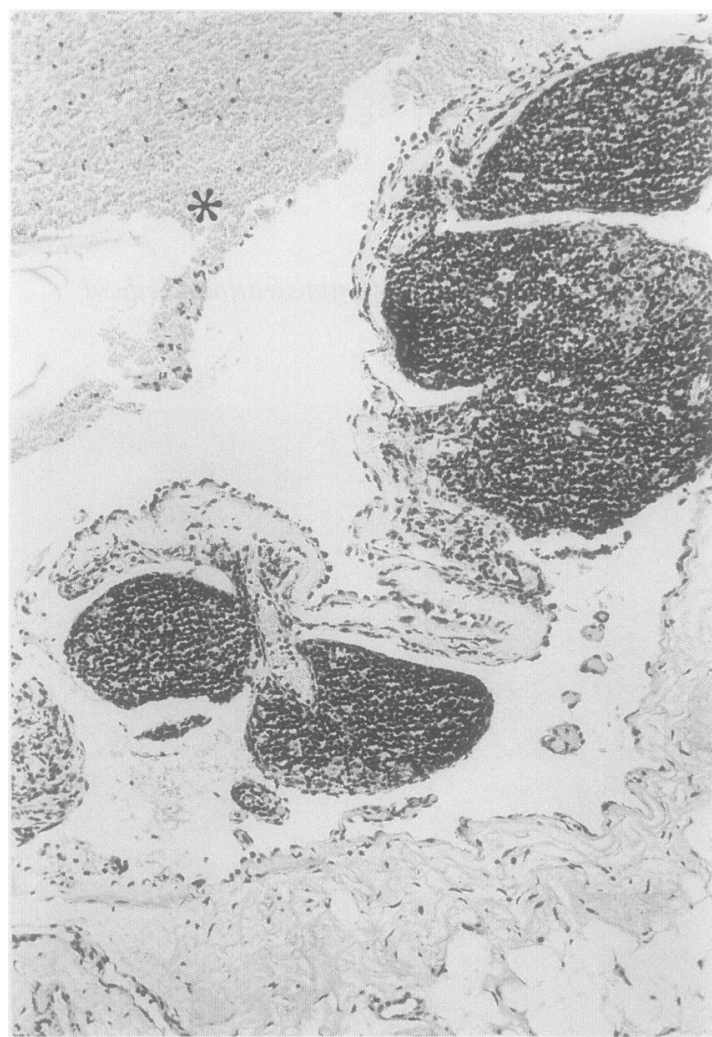

Fig 2 Portion of intrapulmonary cyst wall containing nodular aggregates of lymphoid tissue. Endothelium lines the cyst. The lumen (asterisk) is filled with blood.

(Haematoxylin and eosin.) bled in size within 12 months. Angtuaco $\mathrm{et} \mathrm{al}^{7}$ described an enlarging mediastinal lymphangioma with prominent vascu? lar elements communicating directly with the innominat vein, but no communication with large vessels could be seep in our patient. Secondly, haemoptysis and lung haemo rrhage have not been previously described in association with this lesion. Lymphangiomas frequently have blood within some cysts, presumably because of coexistent haems angiomatous elements, and $\mathrm{Ninh}$ and $\mathrm{Ninh}^{8}$ reporte 5 haemorrhage in $12 \%$ of their series of cystic hygroma, highlighting the interrelationship of lymphatic and vascular ele $\vec{\omega}$ ments. The dramatic haemorrhage seen in our patient ma? be related to the obstruction to pulmonary venous outflow shown by angiography and computed tomography. Such obstruction could increase pressure in the vascular com ponents of the tumour. This case shows that intrapulmonary lymphangiomas may not always follow a benign course iffer adults.

\section{References}

1 Shenoy SS, Barua NR, Patel AR, Culver GJ, Jennings ECe् Mediastinal lymphangioma. J Surg Oncol 1978;10:523-8.

2 Childress ME, Baker CP, Saamson PC. Lymphangioma of the mediastinum. J Thorac Surg 1956;31:338-48.

3 Spencer H. Pathology of the lung. 4th ed. Oxford: Pergamon Press, 1984:107.

4 Laurence KM. Congenital pulmonary cystic lymphangiectasiso $J$ Pathol Bacteriol 1955;70:325-33.

5 Wada A, Tateishi R, Terazawa T, Matsuda M, Hattori Lymphangioma of the lung. Arch Pathol 1974;98:211-3.

6 Wagenaar SJ SC, Swierenga J, Wagenvoort CA. Late presentation of primary pulmonary lymphangiectasis. Thora 1978;33:791-5.

7 Angtuaco EJC, Jimenez JF, Burrows P, Ferris E. Lymphatic venous malformation (lymphangiohemangioma) of medias tinum. J Comp Assis Tomogr 1983;7:895-7.

8 Ninh TN, Ninh TX. Cystic hygroma in children: a report of 128. cases. J Pediatr Surg 1974;9:191-5. 